\title{
Integrating family and school, a challenge to accomplish
}

\author{
Iván Darío Moreno Acero \\ Universidad de la Sabana, Colombia \\ ivanma@unisabana.edu.co \\ Sara Jeaneth Pinto Mantilla \\ Universidad de la Sabana, Colombia \\ sarapima@unisabana.edu.co \\ Martha Isabel Soto Gómez \\ Universidad de la Sabana, Colombia \\ marthasogo@unisabana.edu.co \\ Natalia Holguin Uribe \\ Universidad de la Sabana, Colombia \\ nataliahour@unisabana.edu.co
}

\section{Abstract}

The present study titled "Strategies of Family and School Integration" conducted at the University of La Sabana (Colombia) had two goals: academic research and Action Research (AR). The first objective was to "analyze the family integration strategies into the formation processes within the school context". In order to achieve this objective, 38 parents were interviewed, as well as 12 teachers and 4 students from the Robert Francis Kennedy School IED in Bogota, Colombia. The primary finding indicated that there are no permanent integration strategies that are clear or attractive enough to capture the actors' attention. Moreover, the ones that had been set up had serious structural failures due to the lack of basic organizational criteria, which limited the degree of their effectiveness. The second objective was to "design an effective strategy that integrated the family into the school in order to facilitate and promote the formation processes". To achieve this IA goal, both their experiences and expectations regarding the relation between family and school were recovered. This process facilitated the creation, implementation and evaluation of a strategy that confirmed that the acknowledgment of the actors' interests is fundamental, as well as the fact that all three entities (families, teachers and students) must work collaboratively since they all share the common goal of educating. 
Key words: family, school, strategies, integrate, family school.

Fecha recepción: Noviembre $2014 \quad$ Fecha aceptación: Junio 2015

\section{Introduction}

Velez (2009) proposes that "the family school relationship can be understood as the agreements and practices of cooperation in the various educational efforts, established between parents or guardians and educational institutions were they enroll their children, in order to facilitate the achievement of institutional educational projects "(p. 4). In this way, the relationship between the family and the school seeks to improve the quality of education, to recognize the existence of the first teachers and their role, to build agreements, to help one another and to promote participation of the administrative, executive and academic decisions.

In everyday Colombian school settings, educational actors agree on the urgent strengthening of communication networks, as well as work and support. Students, teachers and parents all agree that when a partnership is established the results are favorable for each and every one of them. Likewise, they are able to recognize the shared duties and responsibilities that come with the educational work field; they accept their role in the formative process and are aware of the importance of establishing agreements that help facilitate the formation of young children and adolescents. Both teachers and families stop blaming each other about the difficulties students have and instead agree that it is their duty to be united in order to solve them. They postulate that they must build a relationship based on respect and cooperation, which is necessary to establish standards and guidelines that allow them to speak the same language.

Within the context of the current research that had the following objectives: A- Analyze the family integration strategies into the formation processes within the school context and BDesign an effective strategy that integrates the family into the school in order to facilitate and promote the formation processes, it was established that it was necessary to consider family and school integration as an educational strategy. This would not only help identify the problem, but 
it would also allow the possibility of generating strategies that would lead to an effective solution and to integrate all educators. Thus, it becomes imperative to pose the problem and its solution within the Action Research (AR) given that it allows the possibility to reflect on the identified problems from both the theory and practice standpoints, based on an enclosed work and through continuous identification and reflection.

The findings of this IA work were the result of observation, reflection, analysis and the discovery of some necessities within the reality of education; one that seeks to be transformed to ensure the wellbeing of all actors identified. From the IA, while the classroom problem is understood the corresponding course of action is designed so that it satisfies the specific needs and hence the transformation of reality known to be problematic (Ramallo and Roussos, 2008, p. 6). Based on this, it was possible to establish the importance of developing strategies that were able to impact and transform the classroom reality, because if it is important to reflect on the pedagogic actions, it is even more important to identify in practice what and which actions are more appropriate in order to link the family to the school or to strengthen the already existing historical partnerships.

\section{THEORETICAL COMPONENT}

The following work categories were established to create the conceptual framework and therefore theoretical basis of this study:

\section{The family}

The family has been analyzed from different areas of social sciences. In each case it is assumed to be a social institution that is in charge of the first socialization processes of the youngest members of a community. Published in the late XX century, Pierpaolo Donati's Manual de la Sociologia de la Familia proposes that this institution be looked at as a relational core. He states that as a social phenomenon, the family must be understood from its own dynamics, the way in which it is constructed and finds its own meaning within a specific historical and cultural context from its own everyday practices (Donati, 2003). 
Regarding Donati's proposal, the family is not understood as a universal concept, but rather as a localized concept, which led him to comprehend the existence of various types of family organization according to its internal structure; nuclear, extended, single-parent, rearranged and jointed or mixed (Tenorio, 2000; Harris, 2001; Rodrigo and Palacios, 2001; Kottak, 2002).

According to different research studies, the Colombian family structure differs depending on the region, cultures and rural or urban settings. In rural settings, the extended family predominates; that in which three generations cohabitate: grandparents, parents and grandchildren. In urban settings, families are generally nuclear, reorganized or mixed. Likewise, the urban family structure differs according to its social status, ethnicity, religious or historical antecedents particular to each culture (Gutiérrez, 1996, Colombian Society of Pediatrics, 1999; Tenorio, 2000: Kottak, 2002; Harris, 2003).

In Colombia, the family is recognized by the Constitution of 1991 as the most important institution in the Colombian legal system. Due to its changing social character over time and for the historical, political, and economic reasons that surround it, it is considered the core of society. It is for this reason that the family institution enjoys constitutional and legal protection. According to Article 42, the family is the fundamental unit of society.

\section{Family and School}

Family and school are fields of training; places habitual socialization and social principles that facilitate the active integration of the youngest members of society. In this case, both institutions fulfill a vital role. Historically speaking, the school emerges as an institution that works alongside the family, as it complements the task of educating its students for life. Family and school both share the responsibility of educating, but having such shared task entails implications that affect, and sometimes, benefit such relationship.

The conflicts that emerge between the two socializing institutions are primarily due to the lack of schedule compatibility between parents and educators, cultural differences that sometimes separate families within the school context, or due to the lack of training from the educators' end 
to establish and maintain closer and assertive relationships among families. Despite of the conflicts that emerge from mutual recognition of the educational role posed by each institution, these conflicts must be resolved, as blaming each other for the lack of inherent responsibility is detrimental only to the students whom are left adrift.

When the conflict of interest is reinforced, the relationship is reduced to the family only having a presence in board meetings, individual and/or group meetings with the tutor, principal, or a certain teacher. On the other hand, the school is limited to tasks, notes or letters that are sent periodically. Both situations are an expression of the state of the relationship. However, it is imperative to understand that the meetings between parents and teachers should be taken as educational opportunities. Therefore, in order to ensure a successful integration it must be taken into account that parents have to be fully embraced; they must be listened to and understood, they must be referred to by using family language, they must be informed not blamed. Furthermore, common objectives must be established, only what works must be highlighted and obstacles must be confronted by monitoring the different situations of educational order.

Public policies have been created to promote an efficient relationship between the family and the school in Colombia. The public policy for the family is conceived as a set of actions that the State makes to provide goods and services to families in general, but targets those who are or might be more vulnerable.

Historically speaking, the first time there was a conversation about the relationship between family and school in Colombia was after the liberal regime was established by the Constitution of Rionegro in 1863, when the radical liberal fraction issued and implemented the Organic Act of Primary Public Instruction of 1870 (here on after, DOIP), given that, as pointed out by Aline Helg, for the first time in the history of Colombia, education was defined as one of the State functions and one of the duties of parents towards their children (Munoz and Ramirez, 2012, p. 188).

The Ministry of National Education (MEN) issued the Decree 1286-1205, which establishes rules for the participation of parents in order to improve the education processes of the public and private establishments. Law 115 Article 7 states the family as the core of society and the 
one primarily responsible for the upbringing of children until the age of majority. The participation of parents in the school is mentioned in the article 23 and 24 of Decree 1860 and Decree 1286 to 1205 , where the rules are established regarding their participation in improvement of the educational process.

It is important to clarify that families are not the only ones obligated to ensure a high quality education. Schools must also generate different strategies that help families get involved in their children's education, opening up a space for interactions that allow the reinforcement of a constructive relationship so that children and adolescents can be educated. The 1098 law of 2006 on the 42 article cites that within the Institutions' obligations, spaces that promote communication between the school and parents must be generated to ensure the educational process.

\section{Family-School Linking Strategies}

Whenever linking strategies between Family and school are being outlined/considered, the goal is to achieve a high standard of education and to guarantee the children's rights, among other standards (Castro and Regattieri, 2012). In Brasil, several proposals have been proposed, such as, "Talking is How People Understand One Another", which develops communication skills with the opportunity to establish advise and agreements. "Present Family Ideal Student" proposes objectives to reduce school evasion and disciplinary issues, as well as to bring the family closer to school. The "Grandparents' Tea" project allows students and families to reassess the importance of older people, their knowledge and experience.

In Buenos Aires the "cooperative" practice allows two ways in which parents can participate: The first, "Critic Participation with Direct Management Interference" has as a main task to establish work policies and to designate the teaching staff. The second, "Critical Participation without Direct Management Interference "has it as its function to assist in classroom tasks (Carriego, 2010, p. 18). 
In a Kindergarten in Chile, a "face to face" and "non-face-to-face" collaboration was established. In the first, mothers work directly in the classroom through lectures, drama and support in pedagogical planning committees. In the second, mothers collaborate in the preparation of the materials needed in the activity room. In this kindergarten in particular, educators manage to innovate and strengthen the exercise of communication and participation with families through the use of the TIC (Caceres and Alegria, 2008).

Implemented in Mexico, "Family Learning" seeks to motivate the intergeneration learning process. Through reading circles, workshops, parent training and cultural events, this strategy aims to strengthen the teaching/learning process, to bring together Family, students and school and to reinforce social participation (Calderon and Coral, 2012)

To be able to focus on the family and to recognize it as a decisive factor in the education process of children and adolescents is a great improvement in the socio-educational field. However, many other research projects propose different integration strategies for both institutions which now appear more distant than ever before. Next, we will quote some of these research projects that aim to encourage the strengthening of this integration.

In their research, "El Apoyo Familiar en el Proceso de Integracion Educativa de Estudiantes con Necesidades Educativas en Condicion de Discapacidad" Fontana; Alvarado; Angulo; Marin and Quiros (2009) show their results obtained through a series of interviews conducted to 120 students from cycles I and II in a public school in Costa Rica. It was concluded that the teachers consider family support important during the educational integration process, since it promotes communication with family members and the development of positive attitudes towards the institution. In the same way, it helps reinforce the students' self-esteem, security and self awareness.

As far as the teacher's role is concerned, Fernandez de Ruiz and Bigott (2011) reported a technological development experience. Its purpose was to develop a support guide to educators in order to satisfy their need to reinforce family and community participation within the initial 
education Luis Ramos Escobar's kindergarten. This helped their educational practices and provided an enjoyable integration experience.

The study led by Murillo (2009), "Estrategias para la Integracion de las Familias en el Mejoramiento de los Aprendizajes Escolares" conducted in three different schools in the Costarican city of San José (Gravillas Santa Martha and San Francisco), it was demonstrated that the integration that's looked for in school settings depends in many cases on the active participation or involvement of all educational agents.

In the "La Relacion con la Familia desde el Nivel de Pre-Escolar, una Variable de Calidad" research lead by Valverde Forttes (2009), school-family integration is seen as an effective strategy that considers the students' self-esteem and supports the emotional bonds with their parents. One of the most important findings during this research revealed that it was only during traditional communication instances with the parents and the already established dynamic that predominates during report card meetings that there was an opportunity to for both teachers and parents to be able to reflect on the formative process.

\section{METHODOLOGICAL COMPONENT}

\section{Population and Sample}

Since the intention was not to obtain statistic data, but rather to collect information through a series of interviews, the non-probability sample of convenience was employed. Due to their connection to the school, the subjects interviewed were able to provide the necessary answers related to this research. The target population, located in IED Robert Francis Kennedy School in Bogota, Colombia was organized as follows: 38 parents, whose ages ranged between the ages 25 and 50 and whom were representatives before the school board. Other parents participating had children attending Middle school. The teachers' age ranged between 30 and 65 years and the 
total number of participating students' was 48. All 48 students formed part of the school board committee.

\section{Methodology}

The qualitative approach was employed to be able to evaluate the participant's personal experience and their expectations associated with the family-school linking strategies. In order to achieve this, various experience recovery mechanisms were employed such as, field notes, audio recordings and photographs (Mack, Woodsong, Macqueen, Guest, Namey, 2005).

The Action Research (AR) methodology was employed. As defined by Elliot (1993), action research is "un estudio de una situación social con el fin de mejorar la calidad de la acción dentro de la misma". In other words, this methodology formalizes teacher inquiry and empowers teachers to leverage their "insider" knowledge to change classroom practice. Its central structure consists of planning, acting, observing and reflecting. These elements were the key to identify the participants' perception on the importance of family and school integration in order to be able to propose a strategy that could also be reflected upon and strengthened.

\section{Instrument}

A semi structured group interview was implemented. According to Vargas (2012, p. 15), this allows a more natural and spontaneous recollection of memories and experiences from the participants, which in return, allows the researcher to capture the richness from the diverse meanings.

All the researchers were involved in the planning and structuring of the interview. Each one of them formulated a series of questions taking into consideration the preexisting categories already established, which were later evaluated and discussed by everyone. Once the questions were defined and the interview's structure was established, three experts in the subject matter were consulted for validation; two of them verified the questions' content and coherence in accordance to the research objective, while the third expert evaluated the qualitative methodological consistency. 
The outcome of the review led to its validation and thus, the instrument's application. The same interview was used to obtain the experiences from the three participants, since it made possible to determine the points of connection and divergence, as well as the way in which each context operates the studied phenomenon. General and specific ethical norms that regarded the interviewed participants were applied during the interview; first, the research's objectives were explained then, a signed consent form was requested from each participant.

\section{Analysis Procedures, which arise from the AR}

\section{Step 1: Background Reflection}

The first step involved the acknowledgement of the discussion's state through a bibliographic tracking system related to the different family-school linking strategies. Various known data bases were consulted such as, Redalyc, Dialnet, SciELO and Scopus, among others. The findings obtained through this tracking system made it possible to built categories and subcategories. These categories are: Family, Family-School and Family-School Linking Strategies.

Step 2: Reflection from the participants' standpoint

Complying with the AR methodology, the instrument used for data collection was decided: a semi-structured group interview, with the means to identify the participants' voices based on the already established categories around the subject matter. The interviews made it possible to recognize and analyze the assessments of teachers, students and families in order to establish a strategy that fulfilled their expectations.

Step 3: Action

A strategy is developed in line with the AR principle. After having analyzed the results obtained from the instrument's application, the proposal for a strategy that comes close to the requirements and suggestions expressed by the three participants during their interventions is 
created. The third step, action, is evidenced through the strategy's application in an environment that provides the necessary conditions to favor the targeted group's participation.

\section{Strategy:}

The strategy involved a role play in which each participant expressed subject matters related to dreams, future plans and expectations. This strategy was built upon the observation and reflection of everyday life at IED Robert Francis Kennedy through the already established interviews. The strategy was implemented after recollecting the three group participants' expectations with regards to the family-school linking strategies. The proposal aimed to create a space in which all the participants (parents, students and teachers) could share personal experiences in an environment where they could remove themselves from their everyday roles. The family-school integration strategy's feedback consisted of an in depth, group interview semi structured by categories, which reveled if the participants' expectations were fulfilled.

Step 4: Reflection from the participants' standpoint

The instrument is applied again to learn more about the participants' own voice. During this step, their experiences from the implemented strategy are collected with the purpose of analyzing the research's gaps and reach.

Step 5: Final reflection on AR's results

The results' analysis occurred in two stages: the first stage consisted of a comparative analysis obtained during the participants' first interview concerning the family, family-school and familyschool linking strategies. The second stage consisted of a comparative analysis from the results obtained during the in depth, semi structured interview. The purpose was to collect the participants' experience about the linking strategy.

The discussion was based on theorists such as Donati, who embraces the concept of family and its repercussion in society, as well as other researchers who have worked on the development of 
family-school linking strategies. The conclusion was based on the analysis of the participants' standpoint and attitude towards the strategy, in addition to their sense of commitment beyond economic and social obligations. Moreover, the tension that exists between some of the participants due to their sense of authority and the way in which they perceive society was also analyzed.

Finally, a set of recommendations were built as a starting point for future research in order to facilitate the strategy developing process. Even though every educational institution, their teachers, students and family members have very different qualities, they all recognize the need of being involved in a strategy that not only allows them to express how they feel, but also where their opinions are taken into consideration.

\section{FINDINGS}

\section{CROSS-TAB ANALYSIS FROM FIRST INTERVIEWS}

\section{FAMILY}

Taking the family into consideration, it was found that educators agree that the family is the main institution responsible for the education and formation of children and young adults. They emphasize that it is within the family structure that the main values and norms that allow social interaction and community living are established. Both parents and teachers refer to the family as follows: E 1: D 2: "throughout history, family has had different concepts and conformations, but its mission has always been the same one; to be the main pillar. The family is the fundamental core of society".

Students also recognize the family as the main institution responsible for a person's formation and the primary source of love and support. The following affirmations corroborate this statement: E 1: E 7: "In my opinion, it is very important because it is the one that gives us the foundations in order to make the decisions were making. The one that provides advice and that is 
primarily what it does. Its initial objective is to support us and guide us in our own evolution while we begin to be; begin to decide and begin our own communal living".

Parents express that families are different from one another and that is in this difference that the various styles of education and upbringing emerge. They also express that families are formed by other people besides the parents, such as grandparents, uncles, etc. who also play a key role in the children's education and upbringing. E 1: M 3: "The difference between families is that we all are different worlds. As we are all different people, we all have a different way of teaching, raising, educating, loving and being. So we are all different".

The interviewed students agree with the parents that each family is different. They assured that just as there are parents committed to their responsibilities, there are others who are not interested in their children's formation and education. E 1: E 2: "Each family is different. For example: there are some parents that are more responsible and take care of their children. Sometimes they exaggerate and don't let them go out the door, but there are other parents that spend their time watching soap operas and when the child says something, the parents tell them to go away or they don't care. There are parents that think about what could happen to their children and others who think their children are a burden".

\section{FAMILY AND SCHOOL}

As far as the relationship between the family and the school is concerned, both students and parents recognize the importance of maintaining a close and cordial relationship even when some difficulties emerge due to extended work shift hours. E 1: M 4: "I base the family's purpose in regards to school, basically looking back to mom and dad. They are the ones that have to be in charge of their children. So, mom and dad must set time aside because they work too much and they have to shift responsibility. What do we refer to, with shift during homework, breakfast, because children can't get if they are hungry, they can't get to school without their supplies, they can't get to school without their homework and they also can't get to school without love, tolerance and respect. So that's the parent's purpose with their children, to help the school with the upbringing. It is our responsibility". 
Parents, students, and teachers all agree that the children's formation is a shared responsibility between the family and school; Communication is key in order to establish norms that allow both institutions to speak one same language. E 1: E 8: "School and family's responsibility is to inculcate values. When something fails at home, let's say the teacher is the one that can help fix what's wrong. I think that's the primary thing, to inculcate values".

All three participants manifest that the difficulties in the school family relationship can be resolved through dialogue. They think that if there is trust between teachers and families it is easier to get closer and to help the students. E 1: M 2: "Little communication or simply lack of communication. I think that what she says (she points out at one of the other mothers) we should all be more aware. Not only about the material things, but to know what is going on with our children in school because outside our homes there is a totally different world. So we don't know very well who their friends are. We don't know their teachers very well or what surrounds them at school".

As mentioned before, it is evident that there are some communication and time management difficulties within the community, that in many cases are interpreted as a lack of interest on behalf of the teachers. There is a tendency to blame others and to not be accountable for ones actions and responsibilities that they have as families in regards to the children's education. $\mathbf{E} 1$ : D 1: "Family-school relationship is affected primarily due to time and lack of communication. It is common for parents to be absent during school meetings. Parents are not interested in family workshops and I think it is a cultural problem and also a lack of interest from the parents".

As far as the relationship between family and school is concerned in Colombia, both teachers and parents talk about the importance of understating and respecting their differences, comprehending and acquiring a common language among students, teachers and families that allows them to establish an agreement. This should be based on the acceptance of the cultural backgrounds of each family. It is important to take into consideration that this school has families form multiple regions of the country that have moved to Bogota for various reasons. $\mathbf{E}$ 1: D 1: "Many of the families are dysfunctional families according to the social concept surrounding the family. We have standard families consisting of mom, dad, and children. Others 
that include grandparents, cousins and uncles, and occasionally, it is unclear who you should talk to. Historically speaking family, participation in this school has been hard given that dad makes a new home; mom makes a new home and both new families have children of their own".

\section{STRATEGIES OF FAMILY AND SCHOOL INTEGRATION}

Considering the benefits of the collaborative work between family-school-students and analyzing the Educational institution's (Robert Francis Kennedy) reality, it can be determined that there isn't enough integration between family ad school. There are several causes. The Teachers and school directors blame the families and they argue that it is because of their lack of interest that it is not possible to achieve integration. E 1: D 0: "There is a problem. Parents don't show up so it is not that the strategies are not being implemented, it is that parents do not want to get integrate in these strategies". As far as the family participation in the school is concerned, it is not possible to generalize. "You see parents that are interested in their children's process, while others must be frequently called by appointment due to critical situations about their children. What worries the school directors is that these parents argue because it is because of lack of time”.

When parents, students and teachers participate in an integration strategy, they mentioned feeling comfortable and taking advantage of it. They recognize the importance and necessity of working together in search of the welfare of children and adolescents. They also recognize that the students are the main beneficiaries when an alliance is formed between the two institutions. E 1: M 7: "Parents' workshops are important. We were not born as experienced parents".

It is evident that there is a need to integrate the family and the school, as a guiding resource in their role as parents and as an opportunity to reflect upon the role that the family has in the educational formation of the students; to be able to recognize themselves as being responsible for the upbringing of individuals capable of relating to others and to live in community. The interviewed parents expressed the importance of rescuing the values that have been lost. Teachers also recognize the importance of integration strategies. They perceive them as a space that provides the opportunity to share experiences, to bring parents teacher and children together, and to get to know the people that spend time with their kids on regular bases. E 1: D 4: "They 
are spaces that not only come and go, but that they can share. So that the dad meets the other dad whose kid is friends with their kid. Safety nets can be established to take care of my friend's child, meaning not only mine is important but all the other ones are too".

Meanwhile the students also recognize the importance of family- school integration. They manifest that this contributes to the academic processes and they would like to see their families more involved in school. E 1: E 3: "As students we needed so we must make up activities so that parents and teachers integrate and take of advantage of that space". E 1: E 5: "The academic and coexisting values seem affected by the absence of the parents' presence... Why? Because there is no support throughout the processes".

Students express their interest in generating spaces that allow them to articulate themselves, to show off their strengths in artistic events so that their parents get to know their hobbies and what they themselves consider talents. They feel that these spaces will allow them to get closer to their families and to share with them what they like to do the most. E 1: E 6: "Let's say that during school report it's not only about delivering information about coexisting values. It turns out to be two hours talking and the parents end up falling asleep. If it is a report card meeting, then it should be more dynamic. Have a talent show for the report card meeting so that they can show off their kids' talents".

They feel like the only interaction that the school offers is focused exclusively on the academic aspects leaving behind the opportunity of sharing with their families in an environment that allows them to get to know how they feel, think in the way in which they relate to others. But the students are not the only ones who manifest this necessity, the teachers also agree. Some teachers express their frustration towards the institution's family-school integration spaces. E 1 E 7: “You would have to schedule them during non business hours and there is no institutional support to compensate us, right? Then, the department of education's structure is so rigid. We are contradicting ourselves. I think it is important to take note of those contradictions that the department of education has".

In the meantime, parent consider it necessary to be able to create spaces in which they can have a dialogue with their children and teachers to get to know them better and to understand their views on the problematic that exist within the institution. They assure that the school does not 
offer these spaces. E 1: M 3: "School boards are created to take care of conflicts, but why not create a school board that is able to recognize a problem even before it exists; a prevention school board. One that support teachers and the notes they send out and to be more aware of the kids instead of just writing down an OK. One that stands against bullying and does not wait until the kid is a drug addict. That would be a very nice strategy in order to open up spaces for workshops that include the kids. Because sometimes our kids do not listen to us".

It is evident the parents recognize themselves as a fundamental aspect of their children's formation and their responsibility. Throughout the research summit all the parents expressed their interest in participating in school family integration strategies. E 1: M 1: "Integrating ourselves with the teachers helps because when their authority is present in the kids' eyes in the form of guidance they do listen. On the other hand, when we approach them they think, oh here they go again. It's different when teachers approach it through workshops".

The students express that they are no linking strategies in their institution and they consider it is important to create spaces that allow families to get closer to the institution. $\mathbf{E}$ 1: $\mathbf{E}$ 3: "I feel it doesn't. The school doe not relate at all with families. Families worry mainly that the school does not complain about their kids even though you need them involved for different reasons related to school. If we are talking about meetings, then I would say that the school should call them and pressure the more so that they can get involved".

\section{CONSTRUCTION, IMPLEMENTATION AND ACHIEVEMENTS- DIFFICULTIES OF THE STRATEGY}

On June $12^{\text {th }}$ at $6 \mathrm{pm}$., the integration strategy was implemented in the JFK institution. 40 students were called with their respective parents as well as the school board representatives. The total attendants were 30 people. 13 of who were students, 14 parents, 2 teachers and 1 counselor. Throughout the research the 3 participants make it obvious that it is unnessary to link family and school, and although they are all aware of how important this task is, it has not yet 
been made entirely possible despite the already established strategies and the teaching community's efforts.

All the participants' interviews reveal how they all feel the need of generating more dynamic, playful and motivating strategies that are engaging and interesting; strategies that help strengthen values and that generate a space that facilitates the integration among parents, teachers and students within a schedule that accommodates everyone's needs.

As mentioned above, the first suggestion states an obvious necessity to provide the teaching community with elements that are engaging and that involve them in a more proactive manner in the school's formative process. The reflection upon the relationship between parents, school and students is made possible by identifying an innovative strategy that is able to transform the preexisting encounters.

The second suggestion comes from the need of rescuing the values that have been lost or forgotten. The participants feel that core values have lost their meaning and that they must be brought reinstituted through a joined effort between the families and school. (E1: M8: "I would like to participate in more group workshops that talk about why we have left our core values behind").

The third suggestion aims to bring parents, teachers and students closer together by creating spaces in which they can interact, that allow them to get to know each other and to identify the common goals and objectives with the purpose of gaining the students' trust.

Finally, the last suggestion responds to all the participants' desire to find the appropriate time to meet in such spaces. Even though they all agree it is important to establish an integration strategy, they all recognize the challenge of finding a time that works for most of them, so that the schedule does not conflict other obligations that are not school related.

Once the objectives have been established, the strategy "the game of life" is created. Its goal is to allow the participants to know each other in order to gain mutual trust. Therefore, the strategy 
consists of an initial stage to break the ice, a second stage that develops a dynamic and playful interaction, and a third stage that facilitates a collaborative effort among all the participants.

"The game of life" strategy begins in a warm space. The participants are offered a cup of hot chocolate accompanied by bread and cheese. The families appear surprised and are more opened to share with others. While they are eating their snacks, attendance is called and the activity is explained. Each participant receives a balloon and a marker so they can write out their names, goals and strategies in order to achieve such goals. Then, the activity is explained. The balloon represents the participants' lives, which they must defend against others and from a nail held by the researchers. The balloon must be in constant movement. It must be thrown by pairs, then quartets and finally by everyone involved without being dropped.

Once the game is finished, the following questions are asked:

- Did anyone end up with their own balloon? If so, how did you manage to do so?

- Was anyone able to read what was written in the balloons when you had them in your hands?

- How did you lose your balloon?

- How did you defend your balloon?

- Was there anyone who did not throw the balloon away? If so, why?

The game's reflection leads the participants to the realization that, just as in real life, many people come to our lives without being acknowledged as people with goals, objectives, necessities, etc. In the same way, they pass through others' lives. Also, it shows how certain threatening situations generate unpredictable reactions in each person; what is for sure is that everyone is willing to do whatever is necessary in order to protect what's theirs.

The third strategy stage is developed through the closeness between the parents and their children. The excuse was to make them ask each other what they had wrote in their balloons with regards to their goals and objectives, and how they were going to achieve them. They were also encouraged to ask themselves what they wanted to change about themselves in order to improve 
their relationships. The final exercise consisted of a short essay in which the teachers wrote to the parents and students; the students wrote to their parents and teachers; and the teachers wrote to the parents and students what they felt needed to change in order to improve their relationship.

The day began with a welcoming greeting and a snack. The activity was then built in accordance to the established protocol complying with the suggestions made by all the participants during their first interviews. The data acquired during the three interviews was analyzed and codified taking into consideration the initial categories proposed at the beginning of the research. The relevant information was use to structure the strategy.

What was established within the strategy with regards to time, structure and attention was made possible. The first element to be analyzed was to evaluate how the snack helped relief some tension and resistance towards the activity itself. The hot chocolate provided a familiar environment in which the participants felt comfortable and were able to break the ice. Another element to be analyzed was why some participants never threw the balloon. One family, composed by mom, dad and daughter kept the balloon in their hands the entire time while covering each other in order to defend it. Others took the activity with ease and didn't have time to write their goals or objectives as they were either snatched away or pinched by the nails held by the researchers. In other cases, aggressive behaviors were witnessed in order to defend the balloon, while other times, participants kept the balloons moving without caring questioning to whom it belonged to. Furthermore, one particular mother's response to the activity was called to be analyzed; she spent the entire time filling out the form. She never inflated her balloon, and of course, she never played the game.

Throughout the interaction, some cases were evidence of the difficulties some parents have to relate to their children. At the same time the interaction among parents and teachers was complicated; in both cases the social and institutional roles are so embedded, that it makes it hard to break out of and to cross boundaries. The social role stereotypes generate gaps and define a hierarchy that is then justified by the position each participant holds in front of others. 
This hierarchy and the social significance that is attributed to each participant within the familyschool interaction are not conducive to achieving integration. Transforming this reality takes strong will, perseverance and an openness to change. This is not to say that persuading the teachers to involve the parents is an easy task; the activity showed how even though some teachers were willing to participate, their attitude towards the integration was a little hesitant. Some had to be approached first by the students or parents.

On the other hand, it is considered that the strategy's dynamics that involved sharing should have taken place at the end of the exercise so that the reflections made while enjoying a hot cup of chocolate could have offered better results. It is possible that the individuals who lost their balloons (their life) would have been able to save it assuming they did not listened clearly to the instructions due to a possible auditory contamination at the beginning of the exercise, when the participants were also being asked to fill out the forms.

The field notes show evidence that the participants are looking forward to the encounter and show interest in getting to know the objective of the activities proposed and how they can benefit from them. They express their gratitude for being able to choose the time of the encounter and they also express feeling pleased to be able to participate in an activity that takes each participant's interaction and participation into consideration.

The researchers participated in each and every single one of the activities developed during the encounter in a way that was not disruptive, while being attentive and engaged in the participants' interactions and reactions.

\section{IN-DEPTH INTERVIEW: CROSS-TAB ANALYSIS FROM SECOND INTERVIEWS}

On July $15^{\text {th }}, 13$ students assisting the applied strategy participated in the in-depth interview. These group of participants were the most interested in continuing their involvement in future strategies that involved getting close to their parents since it allowed them to experience a side of them they did not know before. 
On July $16^{\text {th }}$, the teachers were interviewed, but only one of them decided to participate. Her strategy appreciation was positive; she recognizes the importance of the students' formation process.

On July $17^{\text {th }}$, three parents participated in the in-depth interviews. All of them demonstrated feeling grateful for the space. However, they propose to talk about other subject matters and to have a higher parent and teacher attendance.

\section{FAMILY AND SCHOOL}

Once the integration strategy was implemented, parents and teachers are able to recognize once again the importance of establishing a relationship between the family and school in which the students can be the main beneficiaries. This integration allows both participants to be informed about whatever is going on with the children and young adults and to be supportive during hard times, as well as sharing their goals. E 2: M 1: “It is important to have a relationship between the school and the family so that the children's education can be well rounded; so that we can help them out". E2: D 1: "One of the shared responsibilities is that of teaching values. While they must be taught at home, they must be reinforced at school. The same thing should happen with discipline. We are the ones that educate them in the different subject matters, such as sciences, mathematics, Spanish, etc. but it is the family who should also review these with them in order for them to be able to assimilate the knowledge”.

Families and teachers recognize it is imperative to accompany students throughout their personality growth so that they can build long lasting relationships that don't interfere with their academic success or their values. E 2: D 1: "Assuming there is a continuous effort from the family's end, it is possible to recognize that the work is done. I think it is particularly obvious in the development of the students' personality. If the family shows responsibility towards the student's endeavors, the student himself will display a higher degree of responsibility. In this way, the student won't be easily influenced by others or to risk his academic work. In my opinion, the family influence over the school is high". 
As a general rule, the relationship established between the family and school in Colombia lacks communication and the reinforcement of common values and goals. Some parents work hard towards their children's formation at home but neglect the fact that the school's support makes it easier to alleviate the task at hand. It is evident how they go back and forth arguing that there is a lack of interest or responsibility without taking into consideration each other's stand points. E 2: M 1: "Education begins with the family while knowledge is acquired at school and that is how a child's education is complimented. The values that are taught at home; coexistence, tolerance, etc. sometimes are not taught at school and it acts as a gear. I think it is important for that gear to be there; family and school, because the first education a child receives comes from the family".

These statements are also backed up by some mother family members who perceive that the difficulties that occur during integration strategies are due in big part to upbringing guidelines that are inadequate and to the fact that the children are not always considered the main priority. $\mathrm{E}$ 2: M 1: "Now days, parents are more concerned about giving them cell phones and computers; material things as opposed to affection, what's essential. I' have told my son: I would rather have only sugar water to drink or to live in a tiny room with both parents as long as there is love and dialogue. Some of the people I went to school with grew up with just enough to barely make it and we all managed to get a career. Why? because mom and dad were present. I grew up with just my mom and seven siblings and here we are; we all made it. What is going on? Nowadays material things have become more important. We want to give our kids everything we didn't have growing up. But, what is it that we didn't have? material things? Look at what happens. Why do they become drug addicts? Why do they get involved with the wrong people? Why do they find themselves in places where they don't belong? Where they ruin their lives? because we are not present. Where were we when the teacher said: your child is doing such and such; your child is not surrounded by good friends? We are always defensive and don't recognize our faults".

There is a tendency on behalf of parents and teachers to be defensive whenever they get a comment regarding their roles. They agree it is hard to accept suggestions and to recognize their faults when it comes to the children's education. Communication is complicated and, the 
comments that are meant to be beneficial for the students' sake are disregarded. E 2: D 1: “I think that as individual human beings, we are incomplete. We need others in order to keep learning throughout life and therefore we have to accept the fact schools need the parents to support us from home. Students obviously need their teachers and parents to learn from them, just as parents need the school for guidance in the formation of their children, even though sometimes it is hard to accept".

\section{FAMILY AND SCHOOL INTEGRATION STRATEGY}

The active participation of family members, students and teachers during an integration strategy helps facilitate a space in which awareness, knowledge and trust can be nourished. It acts as a mechanism to enrich the integration experiences and to strengthen interpersonal relationships by recognizing the importance of maintaining families engaged in the academic and coexisting dynamics of an educational institution. E 2: M 2: "I think that the strategies create a sense of trust and security. They reassure our children are in the right path. Communication between parents, students and teachers gets stronger. There is a communication chain, I think”. E 2: D 1: "I think that if such alliance is achieved, it would be phenomenal. When there is that kind of communication present, students are successful”.

On occasion, parents seem apathetic with what is going on at school. However, giving them the opportunity to come closer allows them to get to know and understand the teacher's stand point with respect to their children's education. Parents understand the strategy's importance since it allows the go get to know their children better. Once the integration strategy has been established, parents confirm the encounters do indeed favor their parenting skills and they are aware of their faults during the education and formation process of their children. This can be evidenced in the following statement; E 2: M 1: "I liked the strategy because for instance, my son didn't know my own objectives, because you just don't talk about those things with your children. It's important that they also know how you feel. This gets them involved in their parents' lives. They pull back sometimes because they are our only focus so in a sense they become disabled. They feel disabled and they don't know anything about their parents". 
E 2: D 1: "First, the strategy made it possible to bring the parents closer. Even if they worry about their children, they may lack some necessary tools for their formation. Second, the students are able to witness how their teachers are truly interested in them and their formation process, even when this means finding spaces outside of school hours". Also, it helps value the importance of maintaining a close relationship between family and school as it reinforces the relationship and communication among the participants".

The teacher who participated in the strategy appeared satisfied with the results: E 2: D 1: "If we are able to strengthen our relationship and communication, most definitely the student's path will be easier". E 2: D 1: "I think the name says it all doesn't it? To integrate both institutions so that their communication can be better".

When confronted with the fact that sometimes parents do not participate during integration strategies offered by the school, some parents expressed feeling betrayed by the institution when being invited to attend linking strategies. E 2: M 2: "I would love it for my husband to attend this kind of meetings. What bothers him is that they try to get you in so they can sell you stuff. He says: They bring you in and then they try to sell you books. That's why he didn't come; he really dislikes these kinds of activities. For example, last time there was a meeting, there was a guy talking and finally, they ended up selling books".

The students expressed satisfactory feelings regarding the opportunity of sharing with their families and teachers in the same space. They were collaborative and showed an interest during the strategy's application. E 2: E 4: “well I thought it was great because finally something like this gets done. I don't think there's ever been an activity in this institution in which parents get to share with teachers and students. It was completely different from a repot card meeting. I thought it was super cool because we talked about different subjects. This is how you find different ways of talking”.

Once the strategy was implemented, the students affirm that very few times does the school organize these kinds of activities where they can share parents and teachers. They say it was very interesting; important things were discussed in an interactive manner. They also express that they 
would like for this to happen more frequently and they expressed interest in participating again in the future. E 1: E 3: This activity reminded me that last year, I participated in a forum with parents. I would like to do these kinds of activities more often because parents come and participate. There are parents who are interested in participating”.

After the strategy took place, the participants were satisfied and manifested their desire in continuing to participate in such encounters. These integration spaces offer parents, teachers and students an opportunity to relate to each other in a different way without pressure or hurry. Moreover, it allows them to express their thoughts and opinions on different subjects without feeling judged. These spaces also offer a chance to reflect upon the roles at play and how they are perceived by others. When the participants' were asked the following question: What would you like to change in order to improve interpersonal relationships? The assistants were interested in learning the opinions of others and some of them where even taking notes. E 2: M 1: "These strategies should be implemented during repot card meetings so that those can be more productive. They are one of the few meetings in which parents and teachers are involved so I think those meetings should be more fruitful, maybe we can talk about a subject similar to what our teacher gave us: write something to your child, but don't have it at the end, make it the very first thing. The first thing shouldn't be the note that should be last. The emotional aspect should be first that way people are not feeling rushed since they haven't gotten their report card yet. During that activity they asked us to write a letter to our child; what do you think about your child? That breaks the ice, changes the attitude and you suddenly realize that you love him. That was a nice activity. As an adult, one is less expressive and has a harder time saying: son, I truly love you so writing it down is helpful. When people have something to day they write it down. It's easier. That was a great activity for the teacher to do during the report card meeting. However, it should have been done first, not after everyone already had the report card in their hands because suddenly everyone is in a hurry and wants to leave. They think I have the grades; that's all that matters, when sadly that is far from the truth".

The parents also appeared grateful after the strategy was implemented. There were some disagreements regarding the duration of the activity. While some parents agreed on assisting to shorter meetings, others expressed that they needed more time. E 2: M 3: "I thought it was 
interesting. What she says (she points out at a mother in family1) it was because of lack of time. It was too short to allow us to get into a more dynamic rhythm". E 2: M 6: "Personally, I liked it and I would like to keep doing it. They should happen more often and during these short periods of time".

\section{DISCUSSION}

According to different research studies, family-school linking strategies demonstrate how it is beneficial for parents, students and teachers to participate and establish an efficient form of communicating. Sociologist Donati (2008) describes the family from the viewpoint of relational sociology that identifies itself with public policy by assuming the educational and the emotional roles in a complex global society. In the same way, Bustamante (2013) makes reference to the family as a specific source in which life is generated and developed. Taking into account the definitions of family mentioned above, we find that the participants involved in the process understand it as the principle educational institutional and upbringing of the children.

The teachers refer to the family as their principal way of support, in charge of building identity, teaching core values and providing the means necessary to achieve their personal development. As far as the concepts built around family are concerned, it becomes crucial to reinforce the meaning they assume according to their local context, which can lead to the problematic they face, the transformations it may have gone through and the tensions they experience in their everyday lives.

1098 law of 2000 makes public the obligations regarding the care, development and education of children in the state, family and school. According to Castro \& Regattieri (2012) in order to establish an appropriate integration strategy it should be taken into consideration the motivation to achieve such interaction between family and school, achieve the education's quality and guarantee the children's rights. Moreover, Castro, et al (2012) revealed that the integration experiences allowed establishing four key points of success: "Educating Families", "Opening the school to Family Participation", "Interacting with the Family to Improve the Educational Metrics" and "Including the Students into Context". 
The three groups of participants involved in this investigation all emphasize that it is necessary to establish a link between family-school integration that is motivating to its participants. For instance, creating play based activities to improve the relationship between parents, children and teachers.

The parents' interests are consistent with the statements mentioned above. After listening to the teachers it is evident that they complain about the families for not being able to establish linking strategies due to their lack of interest. In the other hand, students recognize that the school does not offer the spaces to link the family and school and give suggestions that demonstrate the need of attention, recognition and companionship. Among their suggestions are the creations of artistic and sport activities to promote team work and take advantage of each other's strengths to create cooperation awareness in order to achieve common goals. This suggestion shows that they expect to show their parents and teachers that working together will allow them to achieve the goals that perhaps they have not been able to achieve on their own.

Caceres \& Alegria (2008) research, established a collaborative action in which the mothers organized themselves into two types of work: on site and off site. Both types contributed to their education praxis and were able to innovate and restructure the preexisting participation and communication strategies through the use of TIC. The previous research shows a clear linking strategy that enriches the teachers' praxis, as well as the students' formation process. These types of strategies provide an opportunity for both families and educators to get closer without hierarchies or power dynamics of any kind.

Throughout the interviews, the students display the advantages of linking the families into the learning processes and the positive results that these bring to their academic progress, as well as the acquisition of core values which they consider fundamental for life.

It is demonstrated that students, families and educators are interested in finding a linking strategy that responds to their needs. This shows that establishing efficient communication methods is the first step to listen to each participant and bring them together through a strategy that takes their 
opinions and expectations regarding the family-school integration strategy's objectives. The participants consulted, highlight the importance of establishing a linking strategy between family and school as way to reinforce their relationship and bring back the core values that delineate the relations among their social group.

The three group participants all feel that their need to approach, understand and improve relations, are features that must be taken into account when designing a relevant strategy that links the family into the school's formative process. Rather than a rhetorical approach, the strategy must search for an emotional and social connection, given that the participants' priority is to be able to recover core values.

\section{CONCLUSIONS}

Even though the school has proposed several linking strategies for the families, the parents do not show up to the activities due to schedule discrepancies. Other parents express that the linking strategies to the school are not very attractive and are reduced to report card meetings every other month. They manifest that the summits are not attractive either and that the encounters between parents and teachers are usually cold and awkward, with boring and repetitive chats. This causes parents to feel bored and unmotivated to assist any other potential summits. Moreover they want to partake in brief surveys about meeting /summit time schedules and availability to ensure their assistance.

Conversely, educators recognize it is extremely important to include the families into the school. However, it would be necessary to undergo structural changes within the educational system. They express an interest in participating in family-school linking strategies, but these are limited to the school's operational hours.

The teachers propose that the Bogota Secretary of Education (SED) must take charge of supplying this much needed integration and to do so, they must create a space free of 
bureaucracy since they are not willing to undertake such responsibilities. They agree it is important to support the parents in their children's formative process. However, they state that the school does its part in everyday practices. This contradiction is clear; on the one hand, they promote strategies that reinforce involvement and communication, on the other hand, their everyday practice does not witness this mentality. One thing is clear: while the parents' absence is criticized, the reasons behind them are ignored and overlooked and thus, their possible solutions.

When referring to the linking strategies within their actual context, students are very emphatic in recognizing the importance of this alliance and in the lack of interest on behalf of their teachers and parents to get involved. They argue that their parents privilege their jobs since they are the source of income that supports the families. The students recognize the importance of the familyschool linking process as a means to reinforce their core value formation and propose related subjects for future encounters such as "embrace different". They are aware that core values are the key to overcoming obstacles and that is why they suggest topics that relate to this subject.

The students think that the State should take into consideration single mother head households and the challenges they phase as workers; they ask that their underprivileged status be recognized with the means of facilitating their assistance to the school meetings/summits. On the other hand, they are aware that the school promotes core values. However, they understand that while it is a shared responsibility, it is the family's main task to ensure their children's core values prevail. This exposes the rivalry that exists between the family and school and how it negatively impacts the learning strengthen that it is pretended to develop.

Finally, during the three participants' interventions regarding family-school integration strategies appear two factors that hamper their own implementation: time and interest. This is the reason why an integration strategy was suggested, to take into consideration the participants' opinions while diminishing the time and interest factors. Three steps were taken. First, to reconcile the time/schedule issue. Second, to propose a didactic, dynamic and integrative strategy that allows active dialogue between the three participants. Third, to provide "life moments", formative and gathering spaces through the strategy that go beyond and overcome recrimination and resentment. 
A positive aspect resulted from formulating and applying the strategy. We can say both parents and students enjoyed the session. During play based activities, both express their dreams and future plans; they found an opportunity to get to know and perceive intimate aspects they never thought of sharing. Teachers were able to see students in a different way other than sharing a classroom.

Great satisfaction was evidenced from the three participants towards the strategy implementation. They all express they liked the activity and highlight the importance of continuing to create this kind of spaces in school. Parents had a positive response when they were questioned regarding the integration strategy; they expressed the strategy acceptance was due to the fact that it opens up communication with the school and with families in general.

Parents recognize and show interest in structuring and scheduling sessions assuring more engagement and assistance. They think it was great to keep in mind their work schedules, facilitating them to come to the session. Even though the teachers' assistance was low, they also agreed on the effectiveness of the linking strategy. One teacher validated the importance of having the opportunity to meet with parents and students in a play based activities: much different than a report card meeting to review the students' grades.

Students expressed feeling receptive and appreciative towards the integration activity. They were happy during the activity, as they asked to schedule the next one right away as soon as it ended. Once again, we have to say students enjoy spaces in which they can interact with parents and teachers and share ideas related to their formation process. The students' response identifies that the applied strategy covered all the needs touched by the participants, suggesting that the familyschool linking strategies must be in different spaces and at different times other than school hours and preferably must be play based activities.

Also, some parents say the strategy allowed their children to know them a little more. We noted the needs of both participants, in regards to social and relational conditions, need to be addressed collaboratively as expressed by the research. 
The objective of the Action Research is to design an effective family school integration strategy to facilitate and promote the training process of students. Consistently with what was exposed above, the strategy was functional, since its design took into account all concerns that were evident in the participants' interviews, which in the majority of the consulted researches was not identify as a key aspect.

According to Rojas (2009), AR is a type of applied research that takes place in everyday environments and every day work, collecting information from a given reality by specific techniques (Qualitative quantitative) systematically, participatory, thoughtful, comprehensive and critical forms with the main purpose of immediate measure plan adjustments.

In this case, the everyday school life served as a scenario to get to know the participants' perceptions towards Family-School Integration. From this research a linking strategy emerged, which aimed to satisfy the interests of all the participants. After implementing the strategy, the AR reflexivity principle was applied. From this, it was possible to analyze the sense of coherence between what the participants' want and expect in contrast with their commitment and participation in the strategy.

\section{RECOMMENDATIONS}

As practical recommendations, it is suggested that the next meetings are conducted on schedule after school hours, as this facilitates the assistance of parents and students. The fact that food was offered to all participants (Chocolate, cheese and bread) helped begin the strategy with a better attitude. Certain aspects, such as aromatic fruit scents and the decor of the space enabled the participants' motivation to get involved into the activity. It is suggested that when planning a strategy, aspects like food, music and décor must be included as it is the little things that engage people and encourages their participation.

In order to ensure the teachers' participation, it is necessary to establish institutional arrangements and time compensation so they do not feel their labor rights are being violated, or 
that their other commitments, such as work responsibilities and family commitments were ignored.

Recognizing and working around parents' work schedules made them feel important and taken into consideration, which resulted in a higher attendance and commitment to the strategy.

Implementing the strategy in a school classroom facilitated the attendance of families living in the area. It was interesting to see how parents came voluntarily without feeling pressured or forced. For this reason, topics of interest that engage all three participants must be established, which can unfold in a friendly atmosphere that motivates and encourages their attention on integration initiatives. These initiatives should be the result of their own AR reflective process in which the planning, design and application can generate reconciliation spaces between parents, children and teachers.

\section{Bibliography}

Bustamante, T. (2013). Usos y acepciones del concepto familia: Entre el texto y la realidad. Medellín.

Cáceres, C. A. y Alegría, M. D. (2008).Participación de la familia en el jardín infantil estatal: Una mirada desde la vivencia de sus actores. Universum [online]. 2008, 23 (2), pp. 38-65.

Calderón, M., Coral, E. (2012). Aprendizajes en Familia en México Hacia la integración de escuela, familia y comunidad. Centro de cooperación regional para la educación de adultos en América Latina y el Caribe. Crefal. México.

Carriego, C. B. (2010). La participación de las familias: injerencia en la gestión y apoyo al aprendizaje. REICE. Revista Iberoamericana sobre Calidad, Eficacia y Cambio en Educación, 8(3) 50-67. 
Castro, M. y Regattieri, M. organizadoras. (2012). Interacción escuela-familia: insumos para las prácticas escolares. Brasilia: Unesco.

Donati, P. (2003). Sociología de la Familia. España: Eunsa.

Elliot, J. (1993). El cambio educativo desde la investigación-acción. España: Ediciones Morata.

Fernández de Ruiz, K., Biggot, B. (2011). Alianza escuela-familia-comunidad en el jardín de infancia.

Luis Ramos Escobar: Una experiencia de desarrollo profesional docente. Revista de Investigación. 35 (72). Caracas, Venezuela.

Fontana, A., Alvarado, A., Angulo, M., Marín, E., Quirós, D. (2009). El apoyo familiar en el proceso de integración educativa de estudiantes con necesidades educativas en condición de discapacidad. Revista electrónica Educare, XIII. (2) 17-35.

Gutiérrez de Pineda, V. (1996). Familia y Cultura en Colombia. Editorial Universidad de Antioquia.

Mack, N. Woodsong, C. Macqueen, K. Guest, G. \& Namey, E. (2005). Qualitative Research Methods: A Data Collectors Field Guide. North Carolina: Research Triangle Park, Family Health International.

Ministerio de Educación Nacional (2007). Cómo participar en los procesos educativos de la escuela. Colombia: Ed. Sanmartín Obregón \& Cía. Ltda.

Murillo, E. (2009). Estrategias para la integración de las familias en el mejoramiento de los aprendizajes escolares. Universidad Nacional de Educación a Distancia: Costa Rica.

Muñoz, F., Ramírez, L. (2012). Perspectiva microhistórica de una experiencia social: los padres de familia de San Rafael (Pasto) y la escuela liberal caucana, 1876. 
Pérez, C. Betancort, M. \& Cabrera, L. (2013). FAMILY INFLUENCE IN ACADEMIC ACHIEVEMENT. A study of the Canary Islands. Revista Internacional de Sociología. 71

Ramallo, M. \& Roussos, A. (2008). Lo cualitativo, un modelo para la comprensión de los métodos de investigación. Documento de Trabajo $\mathrm{N}^{\circ} 216$, Universidad de Belgrano. Disponible en la red: http://www.ub.edu.ar/investigaciones/dt_nuevos/216_ramallo.pdf

Rojas, A. (2009). La investigación - acción en el aula. Reflexiones de profesionales de la educación. Perú.

Tenorio, M. (2000). Pautas y Prácticas de Crianza en Familias Colombianas. Bogotá: Ministerio de Educación Nacional.

Valverde Forttes, P. (2009). La relación con la familia desde el nivel preescolar: Una variable de Calidad. Canadá: Universite de Montreal.

Vargas, I. (2012). La entrevista en la investigación cualitativa: Nuevas tendencias y retos. Revista Calidad en la Educación Superior. 3 (1).

Vélez, R. (2009). La relación familia-escuela como alianza, aproximaciones a su comprensión e indagación. Medellín, Colombia. Revista Educación Comunicación Tecnología. 3 (6). 